\title{
The Reform of School-based Teacher Training Mode under the Network Environment
}

\author{
Le Zhang ${ }^{1, \text { a }}$ Ying Chen ${ }^{2, b^{*}}$ \\ ${ }^{1}$ North Minzu University, Basic Education Institute, Yinchuan, Ningxia, 750021 \\ ${ }^{2}$ Ningxia Medical University, Yinchuan, Ningxia, 750004 \\ anunlele@126.com, ${ }^{b^{*}}$ zixuan03@163.com
}

\section{Keywords: School-Based Training; Teacher Training; Model Reform; Network; Support Services}

\begin{abstract}
With the rapid development of information technology, the school-based training model of primary and secondary school teachers in the network environment has become a hot field of research and practice. This paper summarizes the design principles of school-based training of primary and secondary school teachers in the network environment, based on the systematic misappropriation of school-based training in primary and secondary schools supported by the existing network environment and the in-depth analysis of the school-based training characteristics of primary and secondary school teachers in the network environment, and designed the network environment to support the school-based, expert leadership, resource sharing, hierarchical management, diversified assessment of primary and secondary school teachers school-based training model, with a view to teachers after-school training, technical support for the professional development of teachers to provide theoretical and practical reference.
\end{abstract}

\section{Introduction}

With the implementation of the national "three links and two platforms" project, many of the school's hardware environment and conditions have been gradually improved, the schools have a certain infrastructure conditions [1] [2] to enable teachers to enjoy high quality resources, Method of school-based training model reform has become a hot spot for primary and secondary school teachers to continue education research. At the practical level, the state promulgated a series of policy documents: "Opinions of the State Council on Strengthening the Construction of Teachers" (2012), "Guidance Opinions of the Ministry of Education on Deepening the Reform of Teacher Training Patterns in Primary and Secondary Schools to Improve Training Quality" (2013) Called for further deepening the reform of primary and secondary school teachers training model, and comprehensively improve the quality of training [3-5]. The traditional school-based training model of primary and secondary school teachers has not adapted to the current teacher training needs. Whether it is research or practice level, the school-based training model of primary and secondary school teachers in the network environment has become a hot spot.

\section{The Survey of School - based Training of Primary and Secondary School Teachers}

Through the literature research found that the researchers have carried out some research on the relevant fields, formed a network environment for post-service teacher training model reform consensus: emphasis on information technology in school-based training role, to promote the construction of systematic network curriculum resources, the quality of resources in the county to build and share, to carry out rural teacher training reform [6-8], the research focused on: teacher blog construction, network curriculum design and development, sharing of resources to build, cross-school communication platform construction category [9] [10].

At the same time, this study holds that most of the literatures have the following misunderstandings about the school-based training of primary and secondary school teachers in the network environment: 1. The school-based training of the network environment is separated from the traditional school-based training, relying entirely on the network, emphasizing the network 
resources, online research, teaching log, etc. the importance of. Ignoring the school-based training "school-based" features, ignoring the school-based training is carried out at the school level to meet the actual development needs of teachers and schools training activities. 2. The network teaching and research, teaching log, learning network courses and other teacher learning activities and network support school-based training confused. The implementation of school-based training requires the training needs of teachers in schools, planning training programs, designing training content, developing training resources, training implementation and evaluation, is a complete process, and network teaching and research, teaching log, learning network courses and other teacher learning activities only can serve as a part of school-based training for network support and cannot replace school-based training as a systematic teacher's continuing education program. 3 . The network support service system and network platform or network confused. Most of the researchers can easily simplify the network support service system as a network platform or network. The research content of the network support service is limited to the network support function of the school-based training, the function of the network platform, the division of the network platform, the realization of the network platform wait. 4. The lack of systematic research on online support for school-based training, in the process of research focused on school-based training to wear a "network" hat, ignoring the school-based training system contained in the various elements and elements of the link. School-based training is a systematic and complete teacher in the process of receiving continuing education, should include the training, training content, training environment and training object of these elements, the study of network-supported school-based training to combine these four elements to carry out cannot separate the network from them.

This study argues that the school-based training supported by the network environment is the school as the main sponsor and organizer. To meet the needs of schools and teachers, with the school as the main place, with the help of training institutions, educational administrative departments and external experts, the use of network resources for school-based training of resources and processes for the design, implementation, management and evaluation of teachers on-the-job training activities. The network resources refer to the resources that can be connected with the school-based training through the network. It can be summarized as human resources and material resources. The human resources mainly refer to: training experts, educational experts (university teachers, local teachers), educational administration departments, resources, including three aspects: school-based training can be used for teachers to learn resources, school-based training to support teachers to learn tools (communication tools, learning management tools, evaluation tools, reflection tools) and support school-based training organizations, management, evaluation the tools and methods.

\section{The Primary and Secondary School Teachers School-Based Training Mode Design under the Network Environment}

Branch argues that the model is a problematic solution or a representation of a real problem, a standardized description of the relationship between the different elements of the system [11]. Researchers at home and abroad have studied the factors influencing the training effect, and have put forward the influence of curriculum resources, learning support service, interaction, learning activities design, evaluation feedback and learners' learning attitude. Motivation has a significant effect on the training effect [12]. Based on this, the author puts forward that in the design of school-based training for primary and secondary school teachers in the network environment, we should focus on: (1) cannot leave school-based training "school-based units, based on and for the development of schools, schools have full autonomy" [13] characteristics, based on the needs of schools and teachers development, through adequate research, to develop a reasonable school-based training objectives, designed to meet the needs of teachers and school-based training content and training. (2) not only to play the traditional environment can be systematic learning knowledge and face to face the advantages of discussion, but also the use of the network to solve the traditional environment of school-based training time is short, less opportunities for communication, teachers cannot meet the individual learning and other issues, enrich the school-based training (3) The 
orientation of the network in school-based training is the support and service of the school-based training process, such as training organization, management, implementation and evaluation, and cannot exaggerate the role of the network in school-based training. Based on the above system, this study puts forward the school-based training model of primary and secondary school teachers in the network environment including trainers, training objects, training content and training environment.

Multi-Level Nested Trainer Team Building Mechanism. In the construction of the school-based training trainers, the training team needs to combine the excellent teachers and outside school teachers to form a training team of theory and practice to form a multi-level nested trainer team, as shown in Fig. By the education administrative departments and school leadership agencies co-ordination, and training experts and local teachers set up school-based training expert guidance team, the school composed of excellent teachers' on-campus training team, according to the actual situation of the school, the development of school-based training programs and programs and the implementation of school-based training. In the process, the expert team to use QQ group, We-Chat, forum and other network interactive tools for school-based training for remote guidance and assistance. This multi-level nested trainer team can optimize the quality of trainers, so that school-based training can accept the guidance of systematic science, is the traditional school-based training in the training of this weak link to strengthen and supplement.

The "Custom Pace" Mixed Training. Mixed learning provides a theoretical basis for teachers' on-the-job education. Combining the advantages of traditional learning with the advantages of network learning, in addition to face-to-face learning in school-based training, we can create a certain learning environment through the network and provide each teacher with the most good learning support, free to choose learning content, develop learning plans, free to arrange learning time, location, access and update knowledge.

It is not the end of the teacher's learning process. After the training, the teachers are allowed to carry out self-development and knowledge transfer. The reverie is the result of the teacher's learning process. Unrealistic to make the training to produce good results and keep it need to focus on training to build a collaborative communication dynamic network environment to support teachers' self-learning to help teachers in the concentration of training time outside the knowledge of the mastery, the existing knowledge and experience and knowledge of internalization and integration. In addition to the centralized training time, teachers in the training platform through the browsing resources, forum discussions, complete works and other forms of self-learning, as a limited focus on training to supplement and extension of self-learning to give learners in time, place, and so on more freedom, full respect for the individual differences in learners can mobilize the initiative and enthusiasm of learners.

Group learning is a group of teachers in accordance with a certain latitude learning group, usually a discipline or a grade of teachers, to learn the training of knowledge, to carry out group discussions, lectures, teaching seminars and other activities to promote teachers to master the training of knowledge and application. In the latter part of the training, the learning group gradually formed a network learning community, combined with teaching practice, selected questions and the use of teachers training workshops and other tools to carry out research.

Network Learning Support Service System. To support the training effect, the network course, personal space, training community, QQ group, cloud resource service platform and other network tools to integrate, the establishment of management, resource sharing, exchange feedback, diagnostic evaluation of the system of learning support service system. The establishment of a dynamic school-based training database, the training of teachers to facilitate and efficient digital management, the main content, including the basic information management, learning path records, learning results show, learning management, performance management. Construction of expert counseling system, the use of network interactive tools to observe the implementation of school-based training, remote assistance to resource teachers, school-based training to guide and control, to identify and solve the problems in school-based training, school-based training organization and implementation guidance advice; subject teaching experts with the network platform to participate in class management, teachers in the discussion area, the work area to give 
some feedback, and to give the guidance of teaching knowledge, the formation of expert-led interactive mechanism to promote teachers depth interaction. The training content system provides a variety of learning materials and resources in the form of micro-video, micro-resources, interactive test, etc., and promotes training through training workshops in a variety of forms of learning materials and resources based on the Moocs concept-based hybrid web-based platform Teachers to strengthen the learning content and thinking, to strengthen the exchange of activities between teachers. Training evaluation is an effective way to ensure the quality of training and improve the effectiveness of training measures [14], the establishment of diagnostic evaluation system, the use of qualitative evaluation and quantitative evaluation of the combination of multiple ways to evaluate the effectiveness of learning, quality evaluation based on training teachers' learning achievement, training reflection, taking electronic archives, group assessment, case analysis and so on. Quantitative evaluation adopts questionnaire survey, social network analysis, content analysis, attitude and behavior of teachers, and so on.

\section{Acknowledgements:}

2016 Ningxia philosophy and Social Sciences (Education) program: Research on the factors influencing the network training of primary and secondary school teachers in Ningxia and the construction of support service system (16NXJC04)

\section{References}

[1] Yang Zongkai, Yang Hao, Wu Di. On the depth of information technology and contemporary education[J]. Education Research, 2014, (3): 88-95

[2] Gansu Provincial Department of Education. Gansu Province education information environment construction research report [R]. Gansu: Gansu Provincial Department of Education, 2012.

[3] Guo Fa [2012] No. 41 document, "The State Council on strengthening the construction of teachers' views"[Z]

[4] Teacher [2013] No. 6 document, "Ministry of Education on the deepening of primary and secondary school teacher training model reform to improve the quality of training guidance" [Z].

[5] Teacher's letter [2014] No. 20 document, "network training and school-based training integration training implementation guide" [Z].

[6] Zhu Xudong. On the reconstruction of rural teacher training system in China[J]. Teacher Education Research, 2011, (6): 1-8.

[7] Zhou Deyi, Yu Fayou, Li Minqiang, Shi Yunfeng, Zhou Zanmei, Xue Jiangang. Rural primary and secondary school teachers training practice - Taking Hunan Province as an example [J]. Educational Research, 2012, (7): 92-97.

[8] Guo Shaoqing, Shi Dawei. Information technology support school-based training research [J]. Modern Educational Technology, 2011, (4): 77-80.

[9] Xiao Weining, Li Danqing. Research on teacher-based training of teachers supporting information technology - a case study of continuing education of primary and middle school teachers in tianhe district in guangzhou [J]. Electrification Education Research, 2010, (5): 33-36.

[10] Liang Weiyan. Based on Web3.0 teacher school-based training platform construction[J]. Continuing education research, 2013, (1): 85-87.

[11] Branch, R.M. Teaching development model analysis [J]. China Audio-Visual Education, 2007, (1): $24-27$. 
[12] Zhao Yan, Zhao Wei, Jiang Qiang.Study on influencing factors of distance training effect of primary and secondary school teachers based on learning and analysis technology [J]. China Electrotechnical Education, 2014 (9): 132-138.

[13] Ma Li. Actively promote the basic education curriculum reform teacher training efforts to create a new situation in continuing education $[\mathrm{J}]$. Primary and secondary school teacher training, 2001, (10): 3-12.

[14] Zheng Li-hai, SHI Da-wei. Effects evaluation of teacher training program - a case study of unicef "teacher training program in disaster area"[J]. Journal of Audio-Visual Education, 2014 (5): 108-113 